\title{
Power Quality and Performance Analysis of Grid-Connected Solar PV System Based on Recent Grid Integration Requirements
}

\author{
Estifanos Abeje Sharew $\mathbb{D}^{1},{ }^{1}$ Habtemariam Aberie Kefale, ${ }^{2}$ and Yalew Gebru Werkie ${ }^{3}$ \\ ${ }^{1}$ Faculty of Technology, Debre Tabor University (DTU), Ethiopia \\ ${ }^{2}$ Faculty of Electrical and Computer Engineering, Bahir Dar University (BDU), Ethiopia \\ ${ }^{3}$ Faculty of Electrical and Computer Engineering, Debre Markos University (DMU), Ethiopia
}

Correspondence should be addressed to Estifanos Abeje Sharew; estifabeje@gmail.com

Received 22 May 2021; Accepted 5 August 2021; Published 12 August 2021

Academic Editor: Leonardo Sandrolini

Copyright (C) 2021 Estifanos Abeje Sharew et al. This is an open access article distributed under the Creative Commons Attribution License, which permits unrestricted use, distribution, and reproduction in any medium, provided the original work is properly cited.

The electrical energy demand is steadily growing, and hence, the integration of photovoltaic system to the distribution networks is also dramatically increasing though it has a significant effect on the network's power quality. The purpose of this paper is to analyze the impact of solar PV integration on the power quality of distribution networks. The study is conducted using ETAP software, taking one of the radial distribution networks available in Bahir Dar city during the peak of connected loads which has the least voltage profile. Furthermore, the optimal location of the PV in the network is done using particle swarm optimization. Accordingly, the appropriate location of the PV system is determined to be the farthest end bus (bus 34). Also, the impact in terms of voltage and current harmonic distortion on the distribution feeder network is comparatively discussed by comparing the distribution system parameters with different penetration levels of solar PV system. The simulation results obtained demonstrate that high harmonic distortion level is injected correspondingly as the penetration capacity of PV system increased which indicates that the solar PV system should be integrating only up to a maximum possible capacity the network can carry. The integration of the PV system beyond this maximum penetration level causes production of high harmonic distortion which adversely affects the system performance. At the maximum penetration level which allows the acceptable harmonic distortion limit, the total voltage harmonic distortion and current demand distortion are found to be $4.97 \%$ and $14.98 \%$, respectively.

\section{Introduction}

Nowadays, the world's power demand is rapidly increasing due to expansion of loads which in turn required clean, safe, and economic energy resources. The exploitation of fossil fuel sources leads to the integration of renewable energy sources such as wind energy and solar energy into the network to enhance power system performance $[1,2]$. Photovoltaic (PV) generation is one of the widely applied forms of renewable power generation which converts the available free solar energy into usable electricity through the process of photovoltaic effect. The PV systems in power networks can be classified as standalone and grid connected based on their applications. Standalone PV systems are able to supply electric power for remote loads that do not have any source to power loads, whereas grid-connected applications can be used to provide energy for both local loads and exchange power with utility grid $[3,4]$. In a grid-tied solar PV system, an inverter alters the DC current from the PV module into alternating current (AC). When the PV system is connected to the grid, it can transmit the extra energy to the grid after satisfying the existing demand. But when the demand is more than the generation, extra energy is obtained from the grid [5]. The grid-tied solar system is shown in Figure 1.

The required capacity of solar power injected to the grid is expressed by penetration level. The penetration level of the solar power is the ratio of an active total generated PV power to the total system power as presented in [7]

PV penetration level $(\%)=\frac{\text { Total generated PV power }(\mathrm{MW})}{\text { Total system power }(\mathrm{MW})} * 100 \%$. 


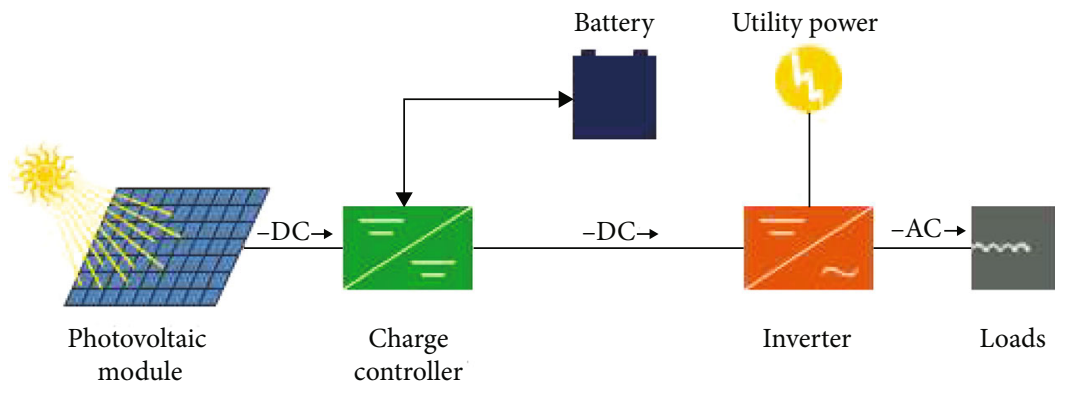

FIgURE 1: Grid-tied solar system [6].

Harmonic distortion is the major undesirable effect that has to be taken into consideration during the operation of grid-connected PV systems. In the PV system, there is an inverter used for conversion of DC current to AC current that injects voltage harmonics and current harmonics to the system which results in power harmonics [8]. The harmonic impacts on the system include production of equipment overheating that leads to equipment failure, increased power loss, system malfunction, equipment protection and operation failure, process disturbance, and voltage fluctuation $[1,9]$.

\section{Literature Review}

Pawar and History [2] in 2019 proposed the harmonic analysis of high-penetration PV system on the distribution grid. The effect of high-penetration PV system in terms of total harmonic distortion (THD) is proposed and analyzed using MATLAB/SIMULINK software for the grid-connected PV system. From the simulation results conducted, the harmonic distortion level increases when high penetration level of PV system is integrated to the network.

Similarly, Farhoodnea et al. [4] in 2012 suggested power quality impact of grid-connected photovoltaic generation system in distribution network. They proposed a $1.8 \mathrm{MW}$ grid-connected PV system in a radial 16 bus test system. The total harmonic distortion is determined to be $14.27 \%$ which is beyond the standard limit.

Also, Kumary et al. [8] proposed modeling and power quality analysis of a grid-connected solar PV system. They suggested on the effect of PV integration in terms of voltage and current harmonic distortion on a three-node residential network using MATLAB/SIMULINK software. The analysis is performed without PV integration, at maximum PV generation with minimum average load and at minimum PV generation with peak load, and the results obtained show that the harmonics of voltage and current are large for far-end node of the feeder compared to nodes near to the distribution transformer. But THD values of current and voltage harmonics are high in case of maximum solar PV generation.

Shafiullah [10] proposed the analysis of harmonics with renewable energy (RE) integration into the distribution network. It investigated the harmonic effect of large-scale renewable energy integration of the distribution network. In the study, $0 \%, 50 \%$, and $100 \% \mathrm{PV}$ penetration levels and hybrid with wind integration (50\% and 100\%) are considered. It is found that high harmonic distortion is generated with the increase in penetration level of RE into the network. For $100 \%$ PV integration and both $50 \%$ and $100 \%$ wind integrations, the current harmonic distortion level was beyond the standard limit but the voltage harmonic distortion was found within the threshold limit.

Sahoo and Kulkarni [9] proposed the impact of photovoltaic penetration on distribution systems. The impact of different penetration levels $(10 \%, 20 \%, 30 \%, 40 \%, 50 \%$, and $60 \%)$ of photovoltaic on the distribution system in terms of voltage harmonics is proposed and analyzed using CYME 7.1 software. The results found that, as the penetration level of PV system increases, the voltage harmonic distortion also increases. The maximum penetration level is determined to be $38.2 \% \mathrm{PV}$ and the harmonics generated are within a standard limit of $5 \%$.

All the previous related literatures reviewed mainly focused on the power quality analysis of grid-connected PV system which this paper also targets. However, this paper also includes the optimal size and location determination of the required PV system.

\section{Resource Potential Assessment of Solar Energy}

The feasibility study of solar PV resource potentials has a significant role for both network-connected PV system and PV standalone system [11]. Sunshine hour indicates the duration of sunshine on a specified location for a given period of time. It can be expressed as an average value for several years. The sunshine hour is taken to be 4-6 hours per day in most of the design [12]. The National Metrology Agency of Ethiopia Bahir Dar branch has registered the sunshine hour data of Bahir Dar city for ten consecutive years [6]. The solar radiation is then determined using the length of sunshine hour of the area. The Angstrom-Prescott estimation model is used to approximate the monthly average daily extraterrestrial solar radiation $[6,13]$.

$$
\begin{aligned}
H_{\mathrm{o}}= & \frac{24}{\pi} G_{\mathrm{SC}}\left(1+\cos \frac{360 n_{\mathrm{d}}}{365}\right) \\
& *\left(\cos \varphi \cos \delta \sin \omega_{\mathrm{s}}+\frac{\pi \omega_{\mathrm{s}}}{180^{\circ}} \sin \varphi \sin \delta\right), \\
\delta= & 23.45^{\circ} \sin \left(360^{\circ} \frac{284+n_{\mathrm{d}}}{365}\right),
\end{aligned}
$$




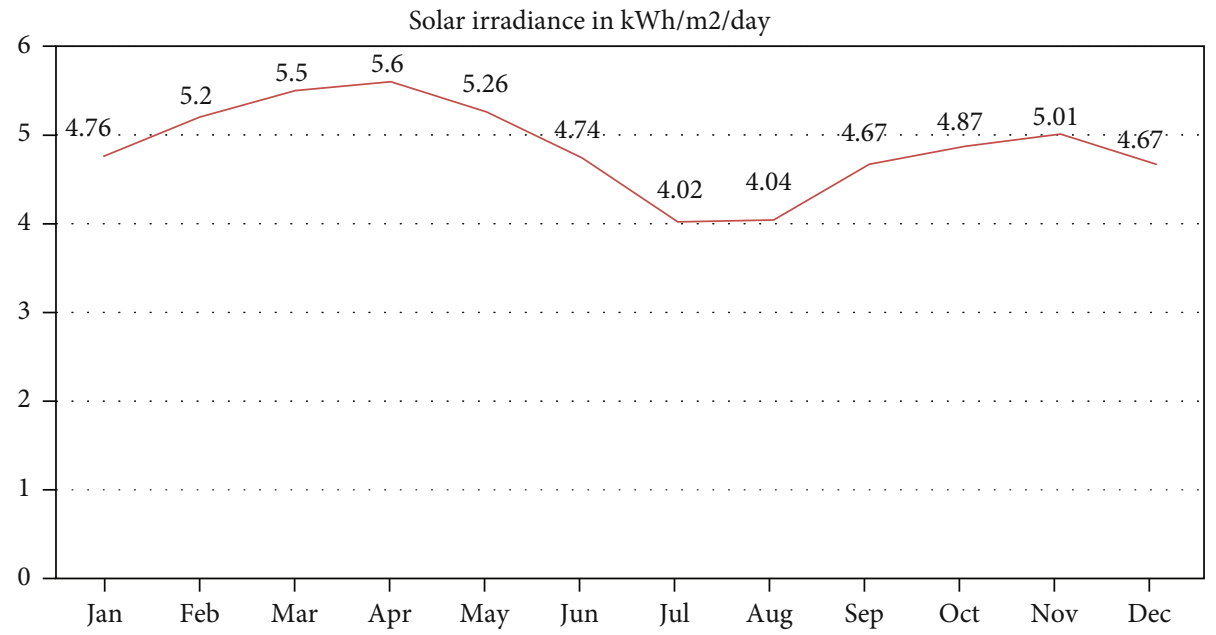

Figure 2: Monthly average insolation of Bahir Dar city.

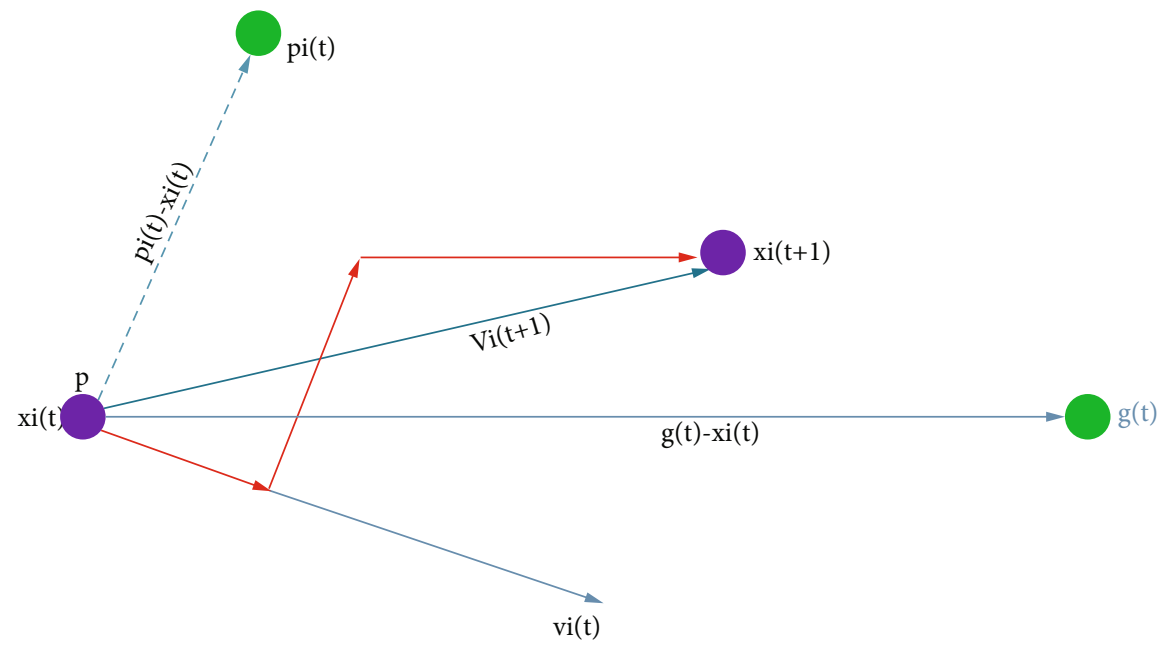

FIGURE 3: Graphical representation of PSO [6].

$\cos =-\tan \varphi \tan \delta$

$$
H=H_{0}\left(a+\frac{b n}{N}\right)
$$

where $G_{\mathrm{SC}}$ is the solar constant $=1.376 \mathrm{~kW} / \mathrm{m}^{2}, \varphi$ is the latitude in degree, $\delta$ is the solar declination in degree, $\omega_{\mathrm{s}}$ is the sunset hour angle in degree, $n_{\mathrm{d}}$ is the day of the year from January 1 to December 31 taking January $1^{\text {st }}$ as $1, N$ is the monthly average of the maximum possible hours of sunshine, $n$ is the monthly average daily hours of sunshine, $H_{\mathrm{o}}$ is the monthly average daily extraterrestrial solar radiation, $H$ is the monthly average daily global solar radiation, and $a$ and $b$ are empirical coefficients.

The solar radiation of Bahir Dar city is calculated accordingly and presented in Figure 2. As it can be noted in the figure, the solar radiation of Bahir Dar city is found in internationally accepted range $\left(4-6 \mathrm{kWh} / \mathrm{m}^{2} /\right.$ day) which implies that this city has abundant solar energy and is feasible for solar PV installation [6].

\section{Optimal Location and Sizing of PV System}

Particle swarm optimization (PSO) is one of the best newly formulated optimization techniques with many attractive features, namely, less number of iteration and execution time to reach the solution [14]. So, in this paper, PSO is applied to determine the optimal location and size of the required solar PV.

4.1. Particle Swarm Optimization. The optimization technique is used to find the best solution for any given circumstances. PSO is a robust stochastic optimization technique based on the movement and intelligence of swarms. It is a population-based search algorithm and is initialized with a population of random solutions, called particles. In a particle swarm optimization algorithm, each member is called "particle," and each particle flies around in the multidimensional search space with a velocity, which is constantly updated by the particle's own experience and the experience of the particle's neighbors or the experience of the whole swarm [15]. Two variants of the PSO algorithm are 


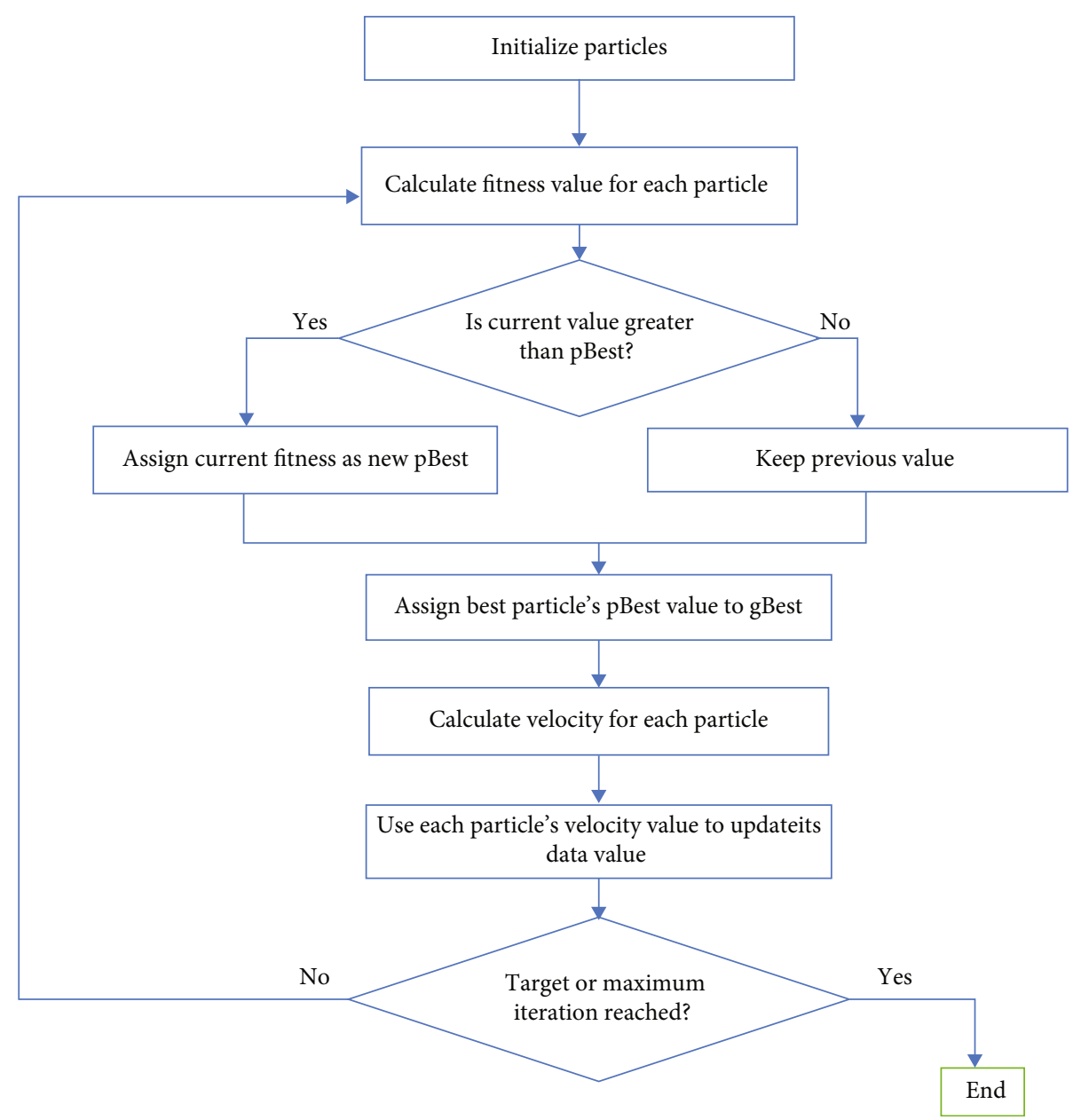

FIGURE 4: Flowchart for the PSO algorithm.

developed, namely, PSO with a local neighborhood and PSO with a global neighborhood. According to the global neighborhood, each particle moves towards its best previous position and towards the best particle in the whole swarm, called global best model and uses a star social network topology. On the other hand, according to the local variant so-called local best, each particle moves towards its best previous position and it reflects a ring social topology.

The particle swarm optimization algorithm shares the basic concepts with the genetic algorithm, in that both of them start by initializing a population of random solutions. However, the PSO system contains a randomized velocity in each potential solution. Each particle initializes first with a random position and random velocity and then keeps track of its coordinates in hyperspace in order to associate with other particles that will combine to achieve the best solution (fitness). This value is called best and must be stored. The pbest is not the only best possible value for the system; there is another best value called gbest. This is the global version of the particle swarm optimizer that keeps track of the overall best value and its position, obtained so far by any of the particles in the same population [16].
Each of the particles tries to update its position based on the following information as it is also graphically shown in Figure $3[6,17]$ :

(i) The particle current positions $\left(X_{i}\right)$

(ii) The particle current velocity $\left(V_{i}\right)$

(iii) The distance between the current position and personal best $\left(P_{\text {pbest }}\right)$

(iv) The distance between the current position and global best $\left(P_{\text {gbest }}\right)$

$$
\begin{gathered}
V_{i j}(t+1)=w * v_{i j}(t)+r_{1} c_{1}\left(p_{i j}(t)-x_{i j}(t)\right)+r_{2} c_{2}\left(g(t)-x_{i j}(t)\right), \\
x_{i j}(t+1)=v_{i j}(t+1)+x_{i j}(t),
\end{gathered}
$$

where $w$ is the inertia weight and $r_{1}$ and $r_{2}$ are random numbers uniformly distributed in the range of 0 to 1 .

The new velocity equation contains three main components. These are 


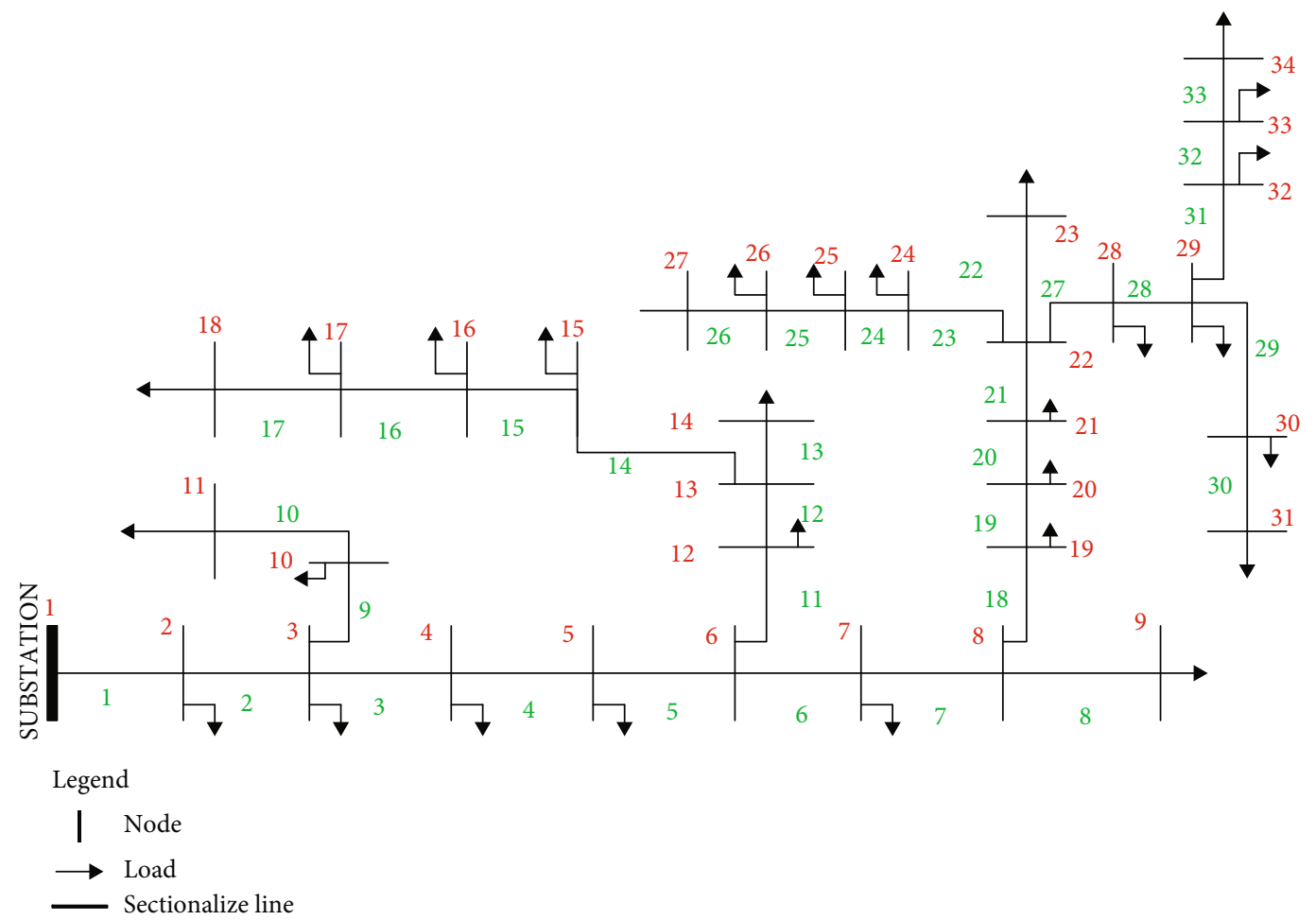

FIGURE 5: Single line diagram of BATA feeder [6].

(i) the inertia term component: $w * v_{i j}(t)$

(ii) the cognitive component: $r_{1} c_{1}\left(p_{i j}(t)-x_{i j}(t)\right)$

(iii) the social component: $r_{2} c_{2}\left(g(t)-x_{i j}(t)\right)$

This new velocity vector translates the previous position of the particles to a new position in the search space. This procedure is repeated until the maximum iteration is reached as shown in Figure 4.

\section{Modeling and Load Flow Analysis of Radial Distribution Network}

A radial configuration network so-called BATA feeder which consists of a total number of 34 buses is selected as a case study for this research work [6]. Bus 1 is the reference bus whereas twenty-nine nodes are connected to loads with the help of stepdown distribution transformer and the remaining four are common coupling nodes as depicted in Figure 5. The total length of overhead distribution line of this feeder is $19 \mathrm{~km}$. The overhead distribution lines are stranded conductor of type AAC-25, AAC-50, and AAC-95, and these overhead stranded conductors are used to distribute $15 \mathrm{kV}$ from Bahir Dar substation II to the distribution transformers [6]. All buses have a voltage level of $15 \mathrm{kV}$, total active power is 1.86 MW, and total reactive power is 1.25 MVAr [6].

5.1. Base Case Load Profile. The base case load and line profiles of BATA feeder are shown in Table 1 [6].
5.2. Backward/Forward Sweep Load Analysis. Forward/backward sweep-based power flow algorithm technique is used for feeders having radial network topology. The forward sweep calculates the node voltage from the sending end to the far end of the feeder and laterals, and the backward sweep is primarily calculating the branch current and/or power summation from the far end to the sending end of the feeder and laterals. In some algorithms, the backward sweeps can also computed node voltages [15].

5.2.1. Algorithm for Forward/Backward Sweep Load Flow. The forward/backward algorithm is developed based on two derived matrices, the bus-injection to branch-current matrix and the branch-current to bus-voltage matrix, and equivalent current injections. For distribution networks, the equivalent current injection-based model is more practical. For the bus, the complex load $S_{i}$ is expressed by

$$
S_{L i}=P_{L i}+j Q_{L i}, \quad i=1, \cdots, N .
$$

Step 1 (backward sweep). For each iteration $k$, branch currents are aggregated from loads to origin. But before finding the branch current, we need to find the current injected at each bus and the bus-injection to branch-current (BIBC) which relates the bus-injected current to the branch current.

The current injection at the $k^{\text {th }}$ iteration of the $i^{\text {th }}$ bus is

$$
I_{i}^{k}=I_{i}^{r}\left(V_{i}^{k}\right)+j I_{i}^{i}\left(V_{i}^{k}\right)=\left(\frac{S_{i}}{V_{i}^{k}}\right)^{*}=\left(\frac{P_{i}+j Q_{i}}{V_{i}^{k}}\right)^{*},
$$


TABLE 1: Line and load data for BATA feeder.

\begin{tabular}{|c|c|c|c|c|c|c|c|}
\hline $\begin{array}{l}\text { Sending node } \\
(i)\end{array}$ & $\begin{array}{l}\text { Receiving node } \\
(j)\end{array}$ & $\begin{array}{c}\text { Conductor } \\
\text { type }\end{array}$ & $\begin{array}{l}\text { Length } \\
(\mathrm{km})\end{array}$ & $\begin{array}{c}\text { Resistance } \\
(\Omega)\end{array}$ & $\begin{array}{c}\text { Reactance } \\
(\Omega)\end{array}$ & $\begin{array}{l}\text { Receiving end load } \\
(\mathrm{kW})\end{array}$ & $\begin{array}{c}\text { Receiving end load } \\
\text { (kVAr) }\end{array}$ \\
\hline 1 & 2 & AAC95 & 1.86 & 0.57381 & 0.399342 & 24.676 & 12.408 \\
\hline 2 & 3 & AAC95 & 0.291 & 0.089774 & 0.062478 & 9.96 & 6.69 \\
\hline 3 & 4 & AAC95 & 0.381 & 0.117539 & 0.081801 & 69.34 & 62.26 \\
\hline 4 & 5 & AAC95 & 0.679 & 0.209472 & 0.145781 & 25.77 & 10.59 \\
\hline 5 & 6 & AAC95 & 0.29 & 0.089465 & 0.062263 & 0.00 & 0.00 \\
\hline 6 & 7 & AAC95 & 1.106 & 0.341201 & 0.237458 & 25.9750 & 15.8430 \\
\hline 7 & 8 & AAC95 & 0.555 & 0.171218 & 0.119159 & 0.00 & 0.00 \\
\hline 8 & 9 & AAC95 & 0.474 & 0.146229 & 0.101768 & 48.00 & 25.80 \\
\hline 3 & 10 & AAC50 & 0.903 & 0.522566 & 0.393889 & 81.71 & 71.11 \\
\hline 10 & 11 & AAC50 & 0.273 & 0.157985 & 0.119083 & 136.74 & 63.84 \\
\hline 6 & 12 & AAC25 & 0.499 & 0.589319 & 0.416416 & 75.45 & 54.22 \\
\hline 12 & 13 & AAC95 & 0.711 & 0.219344 & 0.152652 & 0.00 & 0.00 \\
\hline 13 & 14 & AAC50 & 0.457 & 0.264466 & 0.199343 & 63.90 & 44.65 \\
\hline 13 & 15 & AAC50 & 1.276 & 0.738421 & 0.556591 & 80.40 & 52.80 \\
\hline 15 & 16 & AAC25 & 0.103 & 0.121643 & 0.085954 & 41.98 & 21.80 \\
\hline 16 & 17 & AAC25 & 0.706 & 0.833786 & 0.589157 & 88.28 & 66.93 \\
\hline 17 & 18 & AAC50 & 0.347 & 0.200809 & 0.151361 & 5.08 & 3.06 \\
\hline 8 & 19 & AAC50 & 0.245 & 0.141782 & 0.106869 & 113.00 & 46.82 \\
\hline 19 & 20 & AAC95 & 1.123 & 0.346446 & 0.241108 & 85.07 & 62.20 \\
\hline 20 & 21 & AAC25 & 0.518 & 0.611758 & 0.432271 & 55.60 & 38.99 \\
\hline 21 & 22 & AAC50 & 0.5 & 0.28935 & 0.2181 & 0.00 & 0.00 \\
\hline 22 & 23 & AAC50 & 0.424 & 0.245369 & 0.184949 & 27.22 & 12.02 \\
\hline 22 & 24 & AAC50 & 0.28 & 0.162036 & 0.122136 & 28.04 & 12.59 \\
\hline 24 & 25 & AAC50 & 2.121 & 1.227423 & 0.925181 & 55.81 & 37.96 \\
\hline 25 & 26 & AAC25 & 0.188 & 0.222028 & 0.156886 & 74.60 & 55.23 \\
\hline 26 & 27 & AAC25 & 0.275 & 0.324775 & 0.229488 & 46.52 & 24.54 \\
\hline 22 & 28 & AAC25 & 0.63 & 0.744030 & 0.525735 & 48.40 & 93.80 \\
\hline 28 & 29 & AAC50 & 0.328 & 0.189814 & 0.143074 & 9.30 & 5.50 \\
\hline 29 & 30 & AAC50 & 0.318 & 0.184027 & 0.138712 & 34.45 & 17.37 \\
\hline 30 & 31 & AAC50 & 0.197 & 0.114004 & 0.085931 & 25.78 & 48.74 \\
\hline 29 & 32 & AAC50 & 0.242 & 0.140046 & 0.105561 & 78.50 & 47.80 \\
\hline 32 & 33 & AAC50 & 0.379 & 0.219328 & 0.165319 & 98.00 & 66.00 \\
\hline 33 & 34 & AAC95 & 0.091 & 0.028074 & 0.019538 & 93.50 & 86.00 \\
\hline
\end{tabular}

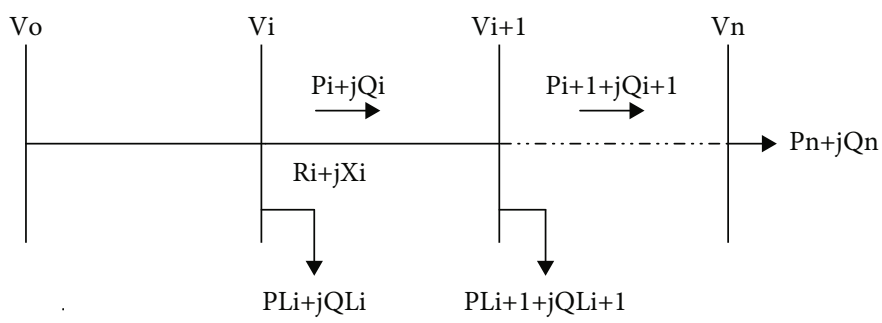

Figure 6: Single line diagram of a main feeder.

where $V_{i}{ }^{k}$ and $I_{i}{ }^{k}$ are the bus voltage and equivalent current injection of the $i^{\text {th }}$ bus at the $k^{\text {th }}$ iteration, respectively.

$I_{i}^{r}$ and $I_{i}^{i}$ are the real and imaginary parts of the equivalent current injection of bus $i$ at the $k^{\text {th }}$ iteration, respectively.
5.3. Problem Formulation. By using the single line diagram of radial distribution system shown in Figure 6, a more simplified recursive equation is developed between nodes $i$ and $i+1$. 


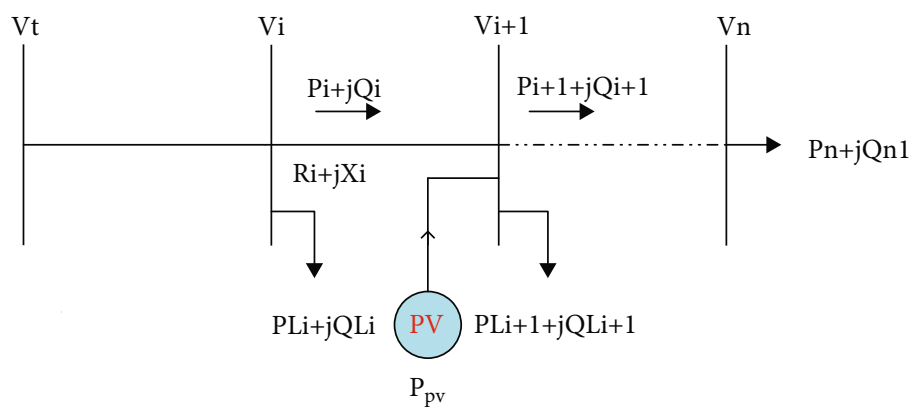

Figure 7: Distribution tie PV system.

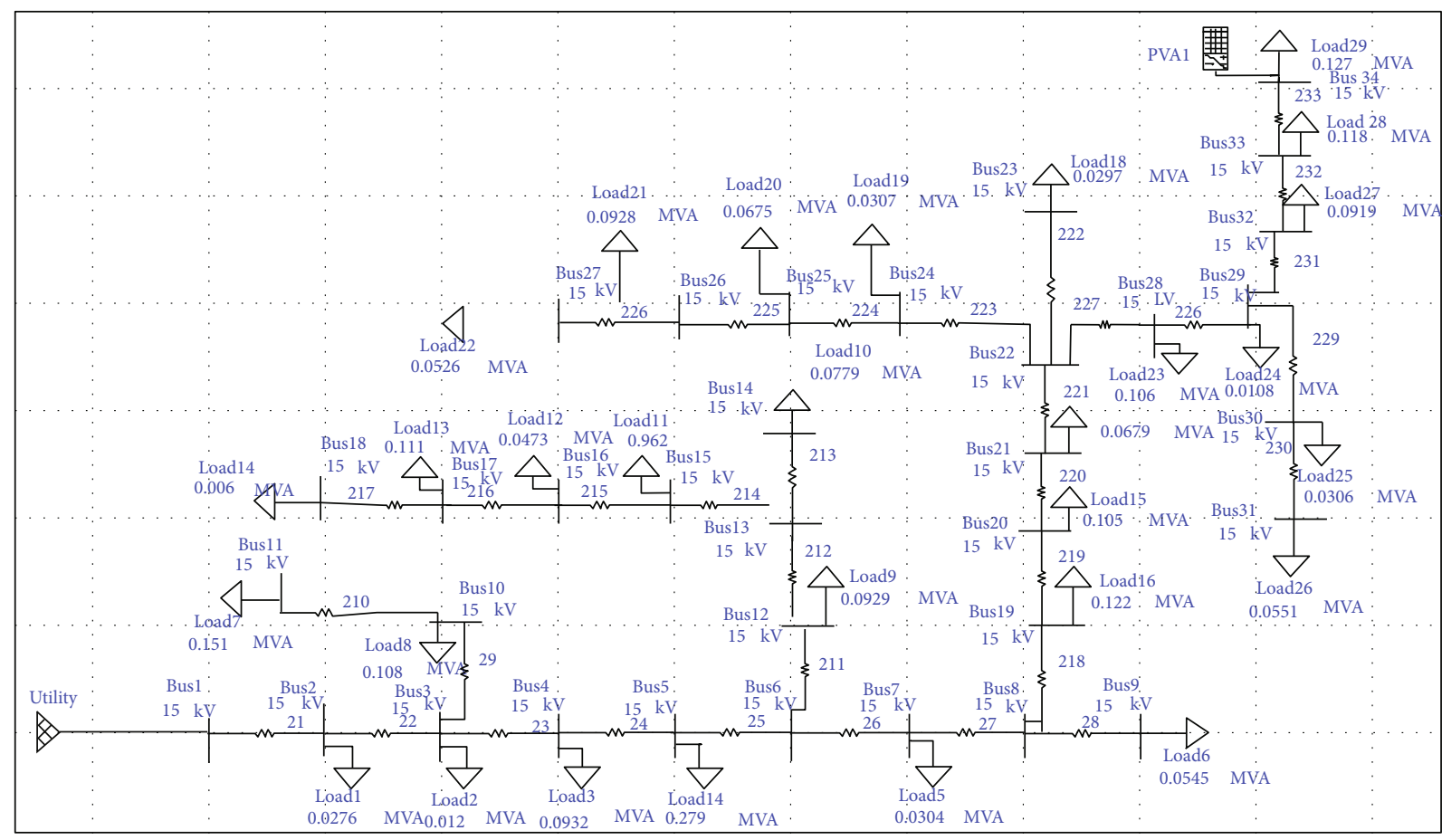

FIGURE 8: Single line diagram of BATA feeder with PV for harmonic analysis.

Active and reactive power between nodes $i$ and $i+1$ before PV system integration can be given as follows:

$$
\begin{gathered}
P_{i+1}=P_{i}-P_{\text {Loss }, i}-P_{L i+1}=P_{i}-\frac{R_{i}}{V_{i}^{2}}\left(P_{i}^{2}+Q_{i}^{2}\right)-P_{L i+1}, \\
Q_{i+1}=Q_{i}-Q_{\text {Loss }, i}-Q_{L i+1}=Q_{i}-\frac{X_{i}}{V_{i}^{2}}\left(P_{i}^{2}+Q_{i}^{2}\right)-Q_{L i+1} .
\end{gathered}
$$

The power loss through the line connecting buses $i$ and $i+1$ can be computed as

$$
\begin{aligned}
& P_{\operatorname{loss}(i, i+1)}=\frac{R_{i}}{V_{i}^{2}}\left(P_{i}^{2}+Q_{i}^{2}\right), \\
& Q_{\operatorname{loss}(i, i+1)}=\frac{X_{i}}{V_{i}^{2}}\left(P_{i}^{2}+Q_{i}^{2}\right) .
\end{aligned}
$$

TABLE 2: Voltage harmonic distortion limits.

\begin{tabular}{lcc}
\hline $\begin{array}{l}\text { Bus voltage } V \text { at } \\
\text { PCC }\end{array}$ & $\begin{array}{c}\text { Individual harmonic } \\
\text { distortion (\%) }\end{array}$ & $\begin{array}{c}\text { Total harmonic } \\
\text { distortion THD (\%) }\end{array}$ \\
\hline$V \leq 1.0 \mathrm{kV}$ & 5.0 & 8.0 \\
$1 \mathrm{kV}<V \leq 69 \mathrm{kV}$ & 3.0 & 5.0 \\
$69 \mathrm{kV}<V \leq 161 \mathrm{kV}$ & 1.5 & 2.5 \\
$161 \mathrm{kV}<V$ & 1.0 & 1.5 \\
\hline
\end{tabular}

The total power losses of the system can be determined by adding up the losses of all the line sections of the feeder under study, which can be given as

$$
\begin{aligned}
P_{T, \text { loss }} & =\sum_{i=1}^{N} \frac{R_{i}}{V_{i}^{2}}\left(P_{i}^{2}+Q_{i}^{2}\right), \\
Q_{T, \text { loss }} & =\sum_{i=1}^{N} \frac{X_{i}}{V_{i}^{2}}\left(P_{i}^{2}+Q_{i}^{2}\right) .
\end{aligned}
$$


TABLe 3: Current distortion limits for system rated $120 \mathrm{~V}$ to $69 \mathrm{kV}$.

\begin{tabular}{|c|c|c|c|c|c|c|}
\hline \multirow[b]{2}{*}{$I_{\mathrm{SC}} / I_{\mathrm{L}}$} & \multicolumn{5}{|c|}{$\begin{array}{l}\text { Maximum harmonic current distortion in percent of } I_{\mathrm{L}} \\
\text { Individual harmonic order (odd harmonics) }\end{array}$} & \multirow[b]{2}{*}{ TDD } \\
\hline & $3 \leq h<11$ & $11 \leq h<17$ & $17 \leq h<23$ & $23 \leq h<35$ & $35 \leq h<50$ & \\
\hline$<20$ & 4.0 & 2.0 & 1.5 & 0.6 & 0.3 & 5.0 \\
\hline $20<50$ & 7.0 & 3.5 & 2.5 & 1.0 & 0.5 & 8.0 \\
\hline $50<100$ & 10.0 & 4.5 & 4.0 & 1.5 & 0.7 & 12.0 \\
\hline $100<1000$ & 12.0 & 5.5 & 5.0 & 2.0 & 1.0 & 15.0 \\
\hline$>1000$ & 15.0 & 7.0 & 6.0 & 2.5 & 1.4 & 20.0 \\
\hline
\end{tabular}

$I_{\mathrm{SC}}=$ maximum short-circuit current at PCC; $I_{\mathrm{L}}=$ maximum demand load current (fundamental frequency component).

For solar PV integrated distribution network as shown in Figure 7, the power loss reduction equations derived above can be modified as

$$
\begin{aligned}
& P_{\mathrm{pv}, \operatorname{Loss}(i, i+1)}=\frac{\left(P_{i-P_{\mathrm{pv}}}\right)^{2}+Q_{i}^{2}}{V_{i}^{2}} R_{i} \text {, } \\
& Q_{\mathrm{pv}, \operatorname{Loss}(i, i+1)}=\frac{\left(P_{i-P_{\mathrm{pv}}}\right)^{2}+Q_{i}^{2}}{V_{i}^{2}} X_{i} \text {. }
\end{aligned}
$$

5.3.1. Operating Limits of PV System Integration. For the installation of PV system integration with the distribution feeder, the systems need to meet certain limiting values. They are listed as follows.

Voltage constraint: according to the IEEE standard, the limit of voltage magnitudes should be maintained between $0.95 \mathrm{pu}$ and $1.05 \mathrm{pu}\left(0.95 \leq V_{i} \leq 1.05\right)$.

Harmonic constraint: the operational range of total and individual harmonic distortion constraints is limited by the maximum limitation based on IEEE standard.

$$
\begin{gathered}
\mathrm{THD}_{v} \leq \mathrm{THD}_{v}^{\max }, \\
\mathrm{IHD}_{v} \leq \mathrm{IHD}_{v}^{\max } .
\end{gathered}
$$
below:

The objective function can be formulated as shown

$$
\begin{array}{ll}
\text { Maximize } & F=W_{1} * \Delta P_{\text {loss }}^{\mathrm{PV}}+W_{2} * \Delta Q_{\mathrm{loss}}^{\mathrm{PV}}+W 3 * \sum_{i=1}^{n}\left(V_{i}-1\right)^{2} \\
\text { Subjected to } & 0.95 \leq V_{i} \leq 1.05 \\
& P_{V} \leq P v^{\max } \\
& Q_{V} \leq Q v^{\max } \\
& W_{1}+W_{2}+W_{3}=1,
\end{array}
$$

where $W_{1}, W_{2}$, and $W_{3}$ are the inertia weights.

In the above equation, the voltage deviation is incorporated as a maximization problem which means it becomes near to zero when each bus voltage magnitude is very close to unity [18].
The solar PV system integrated with the distribution network is also modeled using ETAP software as shown in Figure 8.

\section{Harmonic Distortion Analysis of Distribution System}

In this paper, a fully graphical power system assessment tool called ETAP software is used for harmonic analysis of the distribution system in order to study the harmonic impact of different levels of solar PV system integration into the distribution system.

6.1. Voltage and Current Harmonic Distortions. The harmonics are generated when power supplies, variable frequency devices, or other electronic devices are integrated into the system. Harmonics are an integral multiple of the fundamental frequency mainly produced from electronic devices and nonlinear loads. Production of a high level of harmonic distortion in the network can impact electrical devices including transformers, capacitors, motor, or generator heating, operation of equipment, and other problems which will adversely affect the network performance. Therefore, it is required to reduce the level of harmonics in the system to have a secure and reliable system [2].

Total harmonic distortion is the ratio of the RMS value of total harmonic component of the output voltage and its RMS of the fundamental component. It is a measure of closeness in a shape between the output voltage waveform and its fundamental component. An inverter is used to convert a DC input source to requiring AC output. The quality of the output of the signal can be expressed in total harmonic distortion. The produced harmonic in the system distorts the fundamental waveform. A way of representing signal harmonics with respect to the fundamental waveform is defined as total harmonic distortion. The harmonics produced can be either even or odd. Even and odd harmonics are also related to the number of pulses or paths of conduction. Odd harmonics are produced in the signal when the negative half cycle is similar with positive half cycle but in the negative direction and vice versa for even harmonics [19].

The general equation for the harmonic number is given in

$$
h=(n * p) \pm 1
$$


TABLE 4: Base case voltage profile.

\begin{tabular}{|c|c|c|}
\hline Bus no. & Bus voltage profile values (pu) & $\%$ deviation \\
\hline 1 & 1.00000 & 0.0 \\
\hline 2 & 0.9681 & 3.19 \\
\hline 3 & 0.9631 & 3.69 \\
\hline 4 & 0.9575 & 4.25 \\
\hline 5 & 0.9479 & 5.21 \\
\hline 6 & 0.9439 & 5.61 \\
\hline 7 & 0.9325 & 6.75 \\
\hline 8 & 0.9269 & 7.31 \\
\hline 9 & 0.9267 & 7.33 \\
\hline 10 & 0.9596 & 4.04 \\
\hline 11 & 0.9589 & 4.11 \\
\hline 12 & 0.9371 & 6.29 \\
\hline 13 & 0.9351 & 6.49 \\
\hline 14 & 0.9346 & 6.54 \\
\hline 15 & 0.9298 & 7.02 \\
\hline 16 & 0.9293 & 7.07 \\
\hline 17 & 0.9267 & 7.33 \\
\hline 18 & 0.9265 & 7.35 \\
\hline 19 & 0.9224 & 7.76 \\
\hline 20 & 0.9127 & 8.73 \\
\hline 21 & 0.8973 & 10.27 \\
\hline 22 & 0.8762 & 12.38 \\
\hline 23 & 0.8760 & 12.40 \\
\hline 24 & 0.8750 & 12.50 \\
\hline 25 & 0.8714 & 12.86 \\
\hline 26 & 0.8705 & 12.95 \\
\hline 27 & 0.8700 & 13.00 \\
\hline 28 & 0.8647 & 13.53 \\
\hline 29 & 0.8496 & 15.04 \\
\hline 30 & 0.8491 & 15.09 \\
\hline 31 & 0.8489 & 15.11 \\
\hline 32 & 0.8441 & 15.59 \\
\hline 33 & 0.8398 & 16.02 \\
\hline 34 & 0.8393 & 16.07 \\
\hline
\end{tabular}

where $h$ is the harmonics number, $n$ is any integer, and $p$ is the number of pulses in the circuit.

For a system having full wave inverter, the number of pulses is two so only odd harmonics will exist in full wave rectifiers.

The power quality of the system is frequently measured by the harmonic content of voltage waveform which is the individual harmonic distortion (IHD) and the total harmonic distortion (THD). The individual harmonic distortion of harmonic order $h$ is defined the percentage of voltage at $h$ order with respect to the fundamental voltage signal.

Total harmonic distortion is the ratio of the RMS value of all the harmonic components of the signal to the fundamental signal. The individual harmonic distortion for voltage signals can be expressed as follows [20]:
TABle 5: Base case power losses.

\begin{tabular}{|c|c|c|c|}
\hline From bus & To bus & $\begin{array}{l}\text { Active power loss } \\
(\mathrm{kW})\end{array}$ & $\begin{array}{c}\text { Reactive power loss } \\
\text { (kVAr) }\end{array}$ \\
\hline 1 & 2 & 58.7016 & 40.8532 \\
\hline 2 & 3 & 8.9535 & 6.2312 \\
\hline 3 & 4 & 8.9431 & 6.2239 \\
\hline 4 & 5 & 14.3835 & 10.0101 \\
\hline 5 & 6 & 5.9522 & 4.1424 \\
\hline 6 & 7 & 12.5640 & 8.7439 \\
\hline 7 & 8 & 6.0023 & 4.1773 \\
\hline 8 & 9 & 0.0102 & 0.0071 \\
\hline 3 & 10 & 0.7579 & 0.5713 \\
\hline 10 & 11 & 0.0764 & 0.0576 \\
\hline 6 & 12 & 2.5698 & 1.8159 \\
\hline 12 & 13 & 0.5903 & 0.4108 \\
\hline 13 & 14 & 0.0375 & 0.0283 \\
\hline 13 & 15 & 1.1762 & 0.8866 \\
\hline 15 & 16 & 0.0772 & 0.0545 \\
\hline 16 & 17 & 0.2695 & 0.1904 \\
\hline 17 & 18 & 0.0002 & 0.0001 \\
\hline 18 & 19 & 4.5529 & 3.4318 \\
\hline 19 & 20 & 8.9070 & 6.1988 \\
\hline 20 & 21 & 12.6751 & 8.9563 \\
\hline 21 & 22 & 16.5171 & 2.7939 \\
\hline 22 & 23 & 0.0056 & 0.0042 \\
\hline 22 & 24 & 0.2566 & 0.1934 \\
\hline 24 & 25 & 0.1599 & 0.6506 \\
\hline 25 & 26 & 0.1258 & 0.0889 \\
\hline 26 & 27 & 0.0240 & 0.0170 \\
\hline 22 & 28 & 5.7931 & 4.0934 \\
\hline 28 & 29 & 6.0841 & 0.4786 \\
\hline 29 & 30 & 0.0389 & 0.0293 \\
\hline 30 & 31 & 0.0083 & 0.0079 \\
\hline 29 & 32 & 1.8260 & 0.2368 \\
\hline 32 & 33 & 1.1136 & 0.1997 \\
\hline 33 & 34 & 0.0125 & 0.0087 \\
\hline \multicolumn{2}{|c|}{ Total power loss } & 179.17 & 111.80 \\
\hline
\end{tabular}

$$
\operatorname{IHD}_{v}(\%)=\frac{V_{h, \mathrm{rms}}}{V_{1, \mathrm{rms}}} * 100
$$

Total harmonic distortion for voltage is calculated by the formula given in equation (4)

$$
\mathrm{THD}_{V}(\%)=\frac{\sqrt{\sum_{n=2}^{\infty}\left(V_{n, r m s}\right)^{2}}}{\left(V_{1, \mathrm{rms}}\right)} * 100 .
$$

From the above THD equation, we can have 


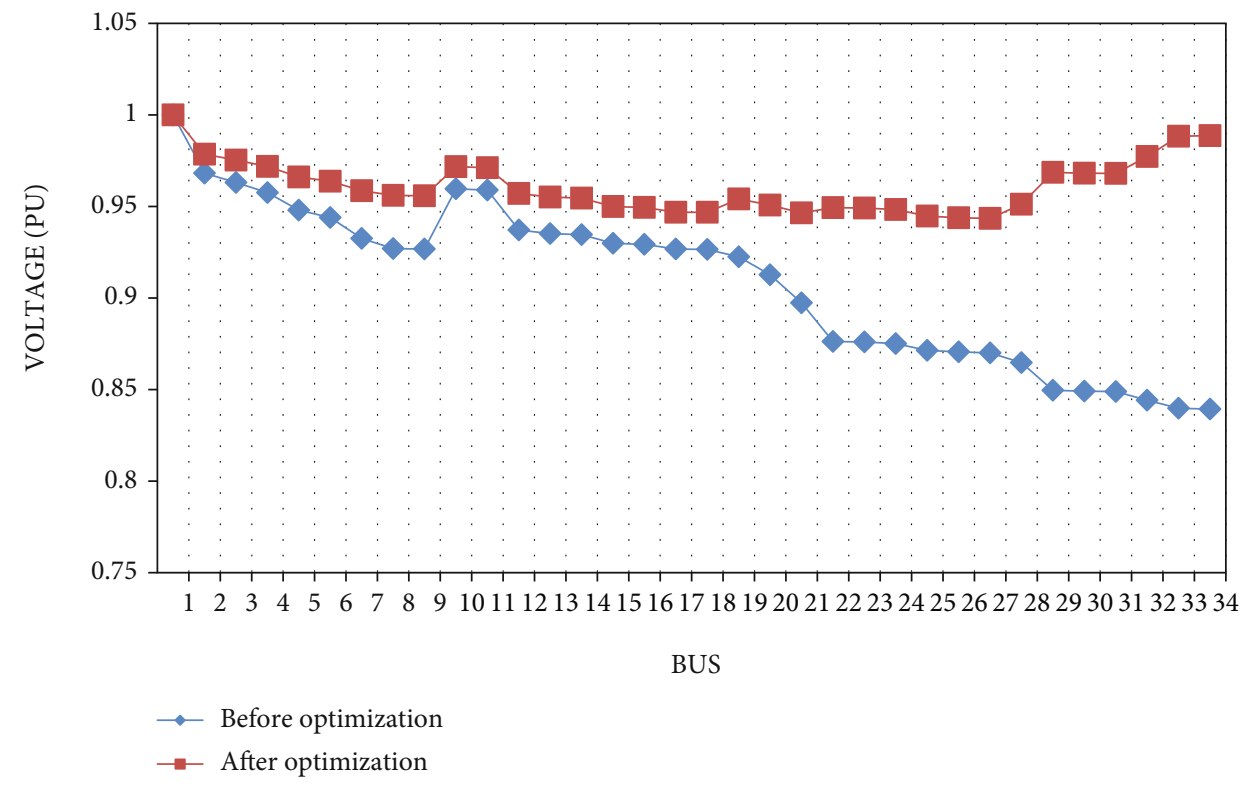

FIGURE 9: The improved voltage profile after optimization.

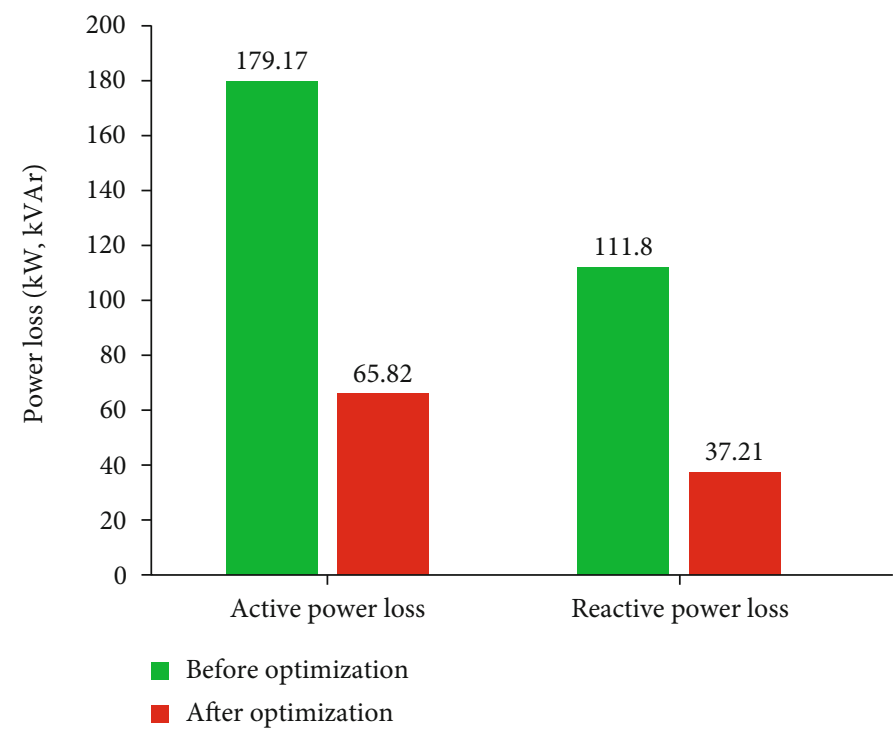

Figure 10: Power loss reduction after optimization.

$$
\begin{gathered}
V_{\mathrm{rms}}=V_{\mathrm{dc}}, \\
V_{1, \mathrm{rms}}=\frac{4 V_{\mathrm{dc}}}{\sqrt{2 \Pi}},
\end{gathered}
$$

where $V_{h, \text { rms }}$ is the rms value of voltage at $h$ order, $V_{n, \text { rms }}$ is the rms value of voltage, and $V_{1, \text { rms }}$ is the rms value of the voltage at fundamental.

The recommended voltage harmonic distortion limits at point of common coupling (PCC) is shown in Table 2 [21].

The recommended current harmonic distortion limits at point of common coupling are presented in Table 3 [21].
At the PCC under normal load operating conditions, the total demand distortion of current can be calculated as [22]

$$
\mathrm{TDD}_{i}=\frac{\sqrt{\sum_{n=2}^{\infty} I_{n}^{2}}}{I_{\mathrm{L}}}
$$

The relationship between total harmonic distortion of current and total demand distortion of current is expressed as

$$
\mathrm{THD}_{i} * I_{1}=\mathrm{TDD}_{i} * I_{\mathrm{L}}
$$


TABLE 6: Voltage THD at each bus for different PV penetration levels.

\begin{tabular}{|c|c|c|c|c|c|c|c|c|c|c|c|}
\hline Buses & $0 \%$ & $10 \%$ & $20 \%$ & $30 \%$ & $40 \%$ & $50 \%$ & $60 \%$ & $70 \%$ & $80 \%$ & $90 \%$ & $100 \%$ \\
\hline 1 & 0.76 & 0.77 & 0.78 & 0.79 & 0.80 & 0.82 & 0.83 & 0.85 & 0.86 & 0.87 & 0.90 \\
\hline 2 & 0.77 & 0.78 & 0.80 & 0.81 & 0.94 & 1.22 & 1.27 & 1.36 & 1.53 & 1.70 & 1.87 \\
\hline 3 & 0.77 & 0.79 & 0.81 & 0.83 & 1.00 & 1.25 & 1.28 & 1.48 & 1.68 & 1.86 & 2.05 \\
\hline 4 & 0.77 & 0.78 & 0.79 & 0.88 & 1.08 & 1.43 & 1.45 & 1.65 & 1.86 & 2.07 & 2.28 \\
\hline 5 & 0.76 & 0.80 & 0.84 & 0.98 & 1.23 & 1.64 & 1.67 & 1.94 & 2.20 & 2.45 & 2.70 \\
\hline 6 & 0.76 & 0.76 & 0.86 & 1.02 & 1.30 & 1.73 & 1.77 & 2.07 & 2.34 & 2.61 & 2.88 \\
\hline 7 & 0.76 & 0.78 & 0.97 & 1.21 & 1.57 & 2.09 & 2.19 & 2.56 & 2.90 & 3.23 & 3.56 \\
\hline 8 & 0.76 & 0.80 & 1.02 & 1.31 & 1.70 & 2.27 & 2.41 & 2.80 & 3.18 & 3.55 & 3.91 \\
\hline 9 & 0.76 & 0.80 & 1.02 & 1.31 & 1.70 & 2.27 & 2.41 & 2.80 & 3.18 & 3.55 & 3.91 \\
\hline 10 & 0.77 & 0.73 & 0.76 & 0.83 & 1.00 & 1.31 & 1.28 & 1.48 & 1.67 & 1.86 & 2.05 \\
\hline 11 & 0.77 & 0.73 & 0.76 & 0.83 & 1.00 & 1.31 & 1.28 & 1.48 & 1.67 & 1.86 & 2.05 \\
\hline 12 & 0.76 & 0.76 & 0.86 & 1.02 & 1.30 & 1.73 & 1.77 & 2.07 & 2.34 & 2.61 & 2.88 \\
\hline 13 & 0.76 & 0.76 & 0.86 & 1.02 & 1.30 & 1.73 & 1.77 & 2.07 & 2.34 & 2.61 & 2.88 \\
\hline 14 & 0.76 & 0.76 & 0.86 & 1.03 & 1.30 & 1.73 & 1.77 & 2.07 & 2.34 & 2.61 & 2.88 \\
\hline 15 & 0.76 & 0.76 & 0.86 & 1.02 & 1.30 & 1.73 & 1.77 & 2.07 & 2.34 & 2.61 & 2.87 \\
\hline 16 & 0.76 & 0.76 & 0.86 & 1.02 & 1.30 & 1.73 & 1.77 & 2.07 & 2.34 & 2.61 & 2.87 \\
\hline 17 & 0.76 & 0.76 & 0.86 & 1.02 & 1.30 & 1.73 & 1.77 & 2.07 & 2.34 & 2.61 & 2.87 \\
\hline 18 & 0.76 & 0.76 & 0.86 & 1.02 & 1.30 & 1.73 & 1.77 & 2.07 & 2.34 & 2.61 & 2.87 \\
\hline 19 & 0.76 & 0.82 & 1.08 & 1.40 & 1.83 & 2.43 & 2.60 & 3.03 & 3.43 & 3.83 & 4.22 \\
\hline 20 & 0.76 & 0.86 & 1.20 & 1.60 & 2.11 & 2.79 & 3.03 & 3.53 & 4.00 & 4.46 & 4.92 \\
\hline 21 & 0.76 & 0.94 & 1.44 & 1.98 & 2.63 & 3.46 & 3.81 & 4.43 & 5.03 & 5.60 & 6.17 \\
\hline 22 & 0.76 & 0.99 & 1.57 & 2.18 & 2.89 & 3.79 & 4.21 & 4.89 & 5.54 & 6.18 & 6.81 \\
\hline 23 & 0.76 & 0.99 & 1.57 & 2.18 & 2.89 & 3.79 & 4.21 & 4.89 & 5.54 & 6.18 & 6.81 \\
\hline 24 & 0.76 & 0.99 & 1.57 & 2.18 & 2.89 & 3.79 & 4.21 & 4.89 & 5.54 & 6.18 & 6.81 \\
\hline 25 & 0.76 & 0.99 & 1.57 & 2.18 & 2.89 & 3.79 & 4.21 & 4.89 & 5.54 & 6.17 & 6.80 \\
\hline 26 & 0.76 & 0.99 & 1.57 & 2.18 & 2.89 & 3.79 & 4.21 & 4.89 & 5.54 & 6.17 & 6.80 \\
\hline 27 & 0.76 & 0.99 & 1.57 & 2.18 & 2.89 & 3.79 & 4.21 & 4.89 & 5.54 & 6.17 & 6.80 \\
\hline 28 & 0.76 & 1.11 & 1.88 & 2.66 & 3.53 & 4.60 & 5.17 & 5.99 & 6.79 & 7.56 & 8.33 \\
\hline 29 & 0.76 & 1.15 & 1.97 & 2.79 & 3.71 & 4.82 & 5.43 & 6.29 & 7.13 & 7.94 & 8.74 \\
\hline 30 & 0.76 & 1.15 & 1.97 & 2.79 & 3.71 & 4.82 & 5.43 & 6.29 & 7.13 & 7.94 & 8.74 \\
\hline 31 & 0.76 & 1.15 & 1.97 & 2.79 & 3.71 & 4.82 & 5.43 & 6.29 & 7.13 & 7.94 & 8.74 \\
\hline 32 & 0.76 & 1.17 & 2.04 & 2.89 & 3.84 & 4.99 & 5.62 & 6.52 & 7.38 & 8.22 & 9.05 \\
\hline 33 & 0.76 & 1.22 & 2.14 & 3.05 & 4.04 & 5.24 & 5.92 & 6.86 & 7.77 & 8.65 & 9.53 \\
\hline 34 & 0.75 & 1.22 & 2.15 & 3.07 & 4.07 & 5.27 & 5.96 & 6.90 & 7.82 & 8.70 & 9.58 \\
\hline
\end{tabular}

\section{Simulation Results and Discussion}

In this paper, harmonic load flow analysis is applied on the selected distribution feeder of Bahir Dar city to determine the level of current and voltage harmonic distortion. The impact of integrating solar PV system into the distribution system in terms of harmonic distortion is analyzed for different penetration levels of the PV system. The total active and reactive powers for the selected radial distribution feeder are 1.86 MW and 1.25 MVAr, respectively. The simulation of the system is carried out with different scenarios (base case, $10 \%$ $\mathrm{PV}$ integration, 20\% PV integration, 30\% PV integration, $40 \%$ PV integration, 50\% PV integration, 60\% PV integration, 70\% PV integration, 80\% PV integration, 90\% PV integration, and $100 \% \mathrm{PV}$ integration).
The voltage profile of the existing network before PV integration is shown in Table 4.

The branch power losses and the total active and reactive power losses of the existing network are presented in Table 5 . From the load flow analysis, the total active and reactive power losses are found to be $179.17 \mathrm{~kW}$ and $111.80 \mathrm{kVAr}$, respectively.

The optimal size of the PV system is determined to be $744 \mathrm{kV}$ using PSO which corresponds to $40 \%$ PV penetration level. The improved voltage profile after optimization is shown in Figure 9.

As shown in Figure 9, the voltage profile of all buses is improved to the accepted limit of operation after $744 \mathrm{~kW}$ $\mathrm{PV}$ is connected at the end bus. At the maximum penetration level (48\%), not only the voltage profile of the system is 


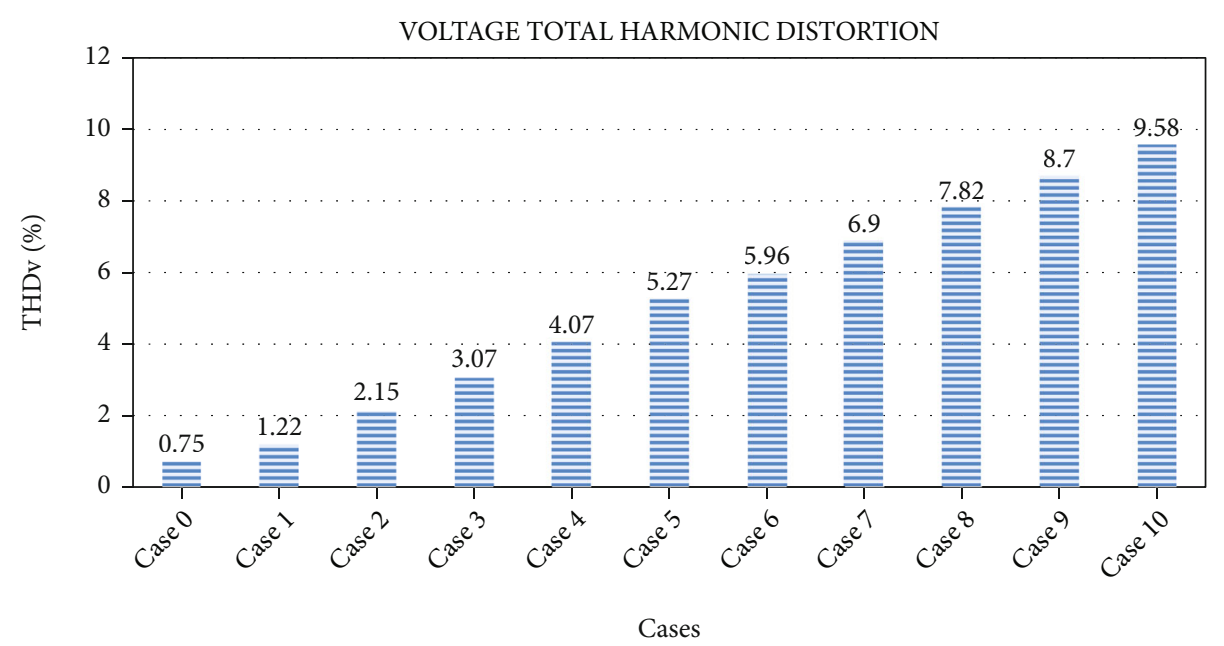

Figure 11: $\mathrm{THD}_{v}$ under different cases at PCC.

TABLe 7: $\mathrm{THD}_{i}$ and $\mathrm{TDD}_{i}$ at PCC for different PV penetration levels.

\begin{tabular}{|c|c|c|c|c|c|c|c|}
\hline Cases & $\mathrm{THD}_{i}$ & $I_{1}(\mathrm{~A})$ & $I_{\mathrm{L}}(\mathrm{A})$ & $I_{\mathrm{SC}}(\mathrm{A})$ & $I_{\mathrm{SC}} / I_{\mathrm{L}}$ & $\mathrm{TDD}_{i}$ & $\operatorname{Max} \mathrm{TDD}_{i}$ \\
\hline Case 0 & 0.56 & 4.77 & 73.33 & 15970 & 217.78 & 0.04 & 15.0 \\
\hline Case 1 & 43.81 & 4.90 & 73.33 & 16030 & 218.60 & 2.93 & 15.0 \\
\hline Case 2 & 37.72 & 11.30 & 73.33 & 16090 & 219.42 & 5.81 & 15.0 \\
\hline Case 3 & 34.84 & 18.18 & 73.33 & 16140 & 220.10 & 8.64 & 15.0 \\
\hline Case 4 & 33.33 & 25.15 & 73.33 & 16200 & 220.92 & 11.43 & 15.0 \\
\hline Case 5 & 32.37 & 32.10 & 73.33 & 16260 & 221.74 & 15.50 & 15.0 \\
\hline Case 6 & 31.73 & 38.99 & 73.33 & 16320 & 222.56 & 15.57 & 15.0 \\
\hline Case 7 & 31.26 & 45.88 & 73.33 & 16370 & 223.24 & 19.59 & 15.0 \\
\hline Case 8 & 30.88 & 52.73 & 73.33 & 16430 & 224.06 & 22.21 & 15.0 \\
\hline Case 9 & 30.56 & 59.49 & 73.33 & 16490 & 224.87 & 24.79 & 15.0 \\
\hline Case 10 & 30.28 & 66.29 & 73.33 & 16540 & 225.56 & 27.37 & 15.0 \\
\hline
\end{tabular}

improved but also the power losses are substantially reduced as shown in Figure 10.

The optimal location of solar PV system is determined at bus 34 using PSO. So bus 34 is taken as a point of common coupling (PCC). As shown in Table 6, as the amount of power injected by the solar PV system into the selected distribution feeder increases, the total harmonic distortion correspondingly increases in each bus. Integrating large size solar PV system into the distribution network can generate high harmonic level and disturbs the system operation. The capacity of solar PV system integrated into the distribution system should be until the level of harmonic generation that does not violate the acceptable limit of operation. The voltage total harmonic distortion at the point of common coupling with different penetration level scenarios is shown in Figure 11 .

The recommended total voltage distortion limit at point of common coupling is shown in Table 2. The bus voltage for this case study is $15 \mathrm{kV}$. So the maximum acceptable total bus voltage harmonic distortion for this case at PCC is 5\%.

The base case total voltage harmonic distortion for the selected distribution feeder at PCC is found to be $0.75 \%$. As shown in Figure 11, case 1, case 2, case 3, and case 4 are within the limit of IEEE standard. But the other cases are exceeding the standard limit. As the level of solar PV power injected to the system increases, the total voltage harmonic distortion also increases. The maximum possible penetration level of solar PV power to the distribution feeder is determined to be $48 \%$ and the voltage total harmonic distortion at this point is found to be $4.97 \%$ which is in the acceptable range of operation.

The current total harmonic distortion of the selected feeder at PCC for each case is shown in Table 7. The total demand distortion is calculated using total harmonic distortion as expressed in equation (17) above. A three-phase fault is created at PCC for determining short-circuit current in each case.

The current total harmonic and demand distortions of the distribution network are shown in Figures 12 and 13, respectively.

The total current harmonic distortion of the network with different penetration levels of solar PV system at point of common coupling is shown in Figure 12, and using these results, the total current demand distortion is determined. 


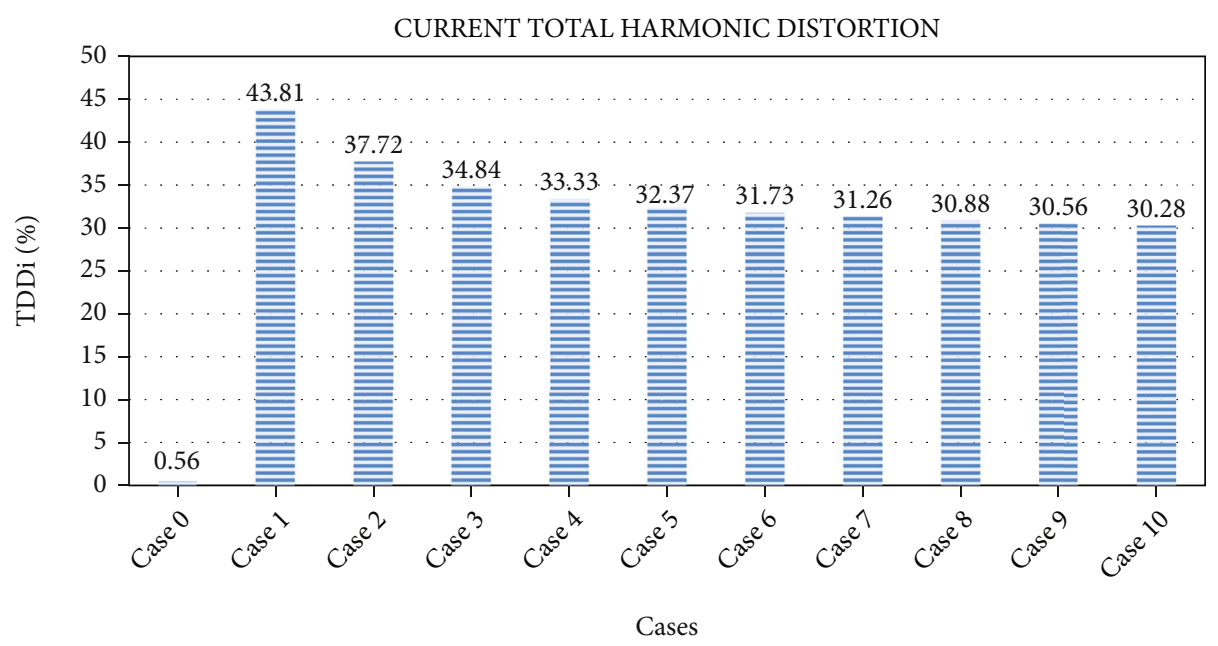

Figure 12: $\mathrm{THD}_{i}$ under different cases at PCC.

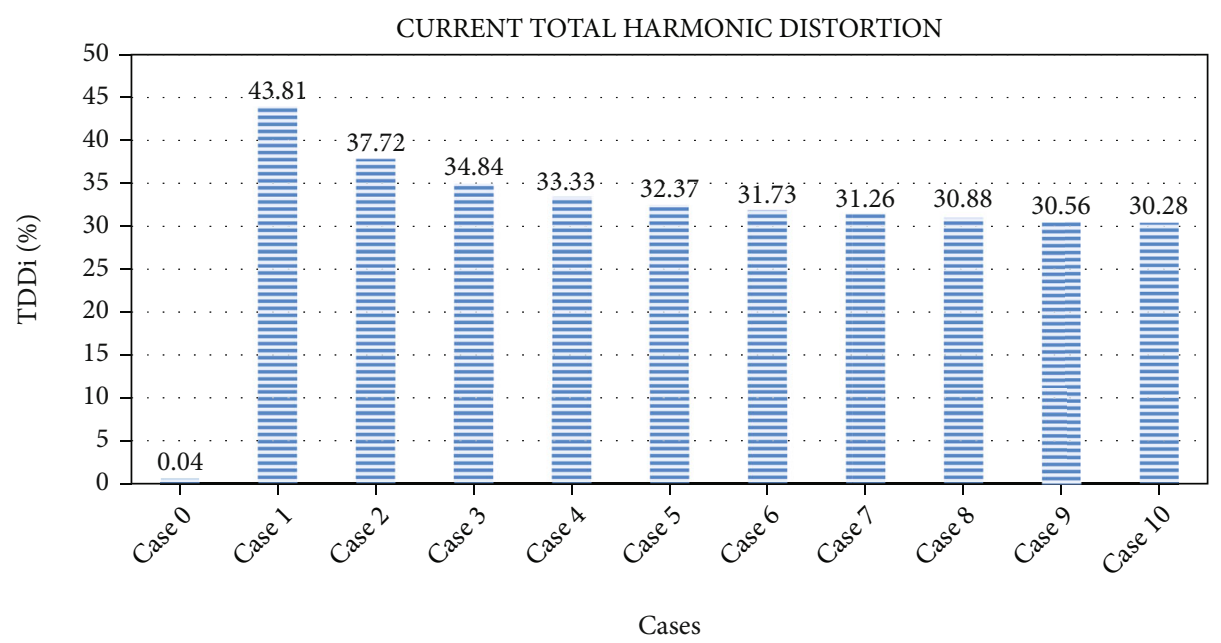

FIgURE 13: $\operatorname{TDD}_{i}$ under different cases at PCC.

The recommended maximum total current demand distortion limit at point of common coupling is shown in Table 2. The maximum possible current demand distortion for this case at PCC is $15 \%$.

The base case total current demand distortion for the selected distribution feeder at PCC is found to be $0.04 \%$. As shown in Figure 13, case 1 , case 2 , case 3 , and case 4 are within the limit of IEEE standard. But the other cases are exceeding the standard limit. As the level of solar PV power injected to the system increases, the total current demand distortion also increases. The maximum possible penetration level of solar PV power to the distribution feeder is found to be $48 \%$ and its total current demand distortion is $14.98 \%$ which is within the limit of the threshold value.

\section{Conclusion}

In this paper, 34 buses of Bahir Dar distribution feeder are taken into consideration to study the power quality of solar PV system connected with the distribution system in terms of harmonic distortion. The harmonic load flow analysis is deployed to determine the level of voltage and current harmonic distortion using ETAP software. The optimal location of the solar PV system is determined to be bus 34 by using PSO. The different penetration levels of solar PV system integration into the feeder are considered to demonstrate the level of harmonic distortion.

The solar PV system should be integrated into the distribution network only up to the maximum possible capacity that the network can carry. The maximum penetration level is determined to be $48 \%$ by considering the total voltage harmonic distortion and current demand distortion. The integration of the PV system above the maximum penetration level adversely affects the system performance. At $48 \%$, which is the maximum penetration level, the total voltage harmonic distortion and current demand distortion are found to be $4.97 \%$ and $14.98 \%$, respectively. Generally, the integration of nonoptimal solar PV system into the distribution network causes power quality problems. 


\section{Data Availability}

Data can be accessed via author request.

\section{Conflicts of Interest}

The authors declare that they have no conflicts of interest.

\section{References}

[1] M. M. El-Sayed, A. A. A. El-Ela, and R. A. El-Sehiemy, "Effect of photovoltaic system on power quality in electrical distribution networks," in 2016 Eighteenth International Middle East Power Systems Conference (MEPCON), Cairo, Egypt, 2016.

[2] S. Pawar and M. History, "Harmonic analysis of high penetration PV system on distribution network," International Journal of Applied Engineering Research, vol. 6, no. 6, pp. 401408, 2019.

[3] L. Xiong, M. Nour, and E. Radwan, "Harmonic analysis of photovoltaic generation in distribution network and design of adaptive filter," International Journal of Computing and Digital Systems, vol. 9, no. 1, pp. 77-85, 2020.

[4] M. Farhoodnea, A. Mohamed, H. Shareef, and H. Zayandehroodi, "Power quality impact of grid-connected photovoltaic generation system in distribution networks," in 2012 IEEE Student Conference on Research and Development (SCOReD), Pulau Pinang, Malaysia, 2012.

[5] C. Shiva, R. Bhavani, and N. R. Prabha, "Power quality improvement in a grid integrated solar PV system," in 2017 IEEE International Conference on Intelligent Techniques in Control, Optimization and Signal Processing (INCOS), Sivakasi, Tamilnadu, India, 2017.

[6] H. A. Kefale, E. M. Getie, and K. G. Eshetie, "Optimal design of grid-connected solar photovoltaic system using selective particle swarm optimization," International Journal of Photoenergy, vol. 2021, Article ID 6632859, 9 pages, 2021.

[7] S. Eftekharnejad, V. Vittal, Heydt, B. Keel, and J. Loehr, "Impact of increased penetration of photovoltaic generation on power systems," IEEE Transactions on Power Apparatus and Systems, vol. 28, no. 2, pp. 893-901, 2013.

[8] S. V. S. Kumary, V. A. A. M. T. Oo, G. M. Shafiullah, and A. Stojcevski, "Modelling and power quality analysis of a grid-connected solar PV system," in 2014 Australasian Universities Power Engineering Conference (AUPEC), Perth, Western Australia, 2014.

[9] R. Sahoo and P. S. U. Kulkarni, "Impact of photovoltaic penetration on distribution systems," International Journal of Applied Engineering Research, vol. 14, no. 11, pp. 2596-2601, 2019.

[10] A. G. M. Shafiullah, "Analysis of harmonics with renewable energy integration into the distribution network," in 2015 IEEE Innovative Smart Grid Technologies - Asia (ISGT ASIA), Asia, 2015.

[11] R. O. Bawazir and N. S. Cetin, "Comprehensive overview of optimizing PV-DG allocation in power system and solar energy resource potential assessments," Energy Reports, vol. 6, pp. 173-208, 2020.

[12] N. Farahiah, B. Ibrahim, Z. Bin, A. Bakar, W. Suhaifiza, and B. W. Ibrahim, "The feasibility study of solar PV lighting: In Universiti Teknologi MARA Sarawak," in 2016 IEEE Industrial Electronics and Applications Conference (IEACon), pp. 92-96, Kota Kinabalu, Malaysia, 2016.
[13] S. Podder, R. S. Khan, S. Ashraful, A. Mohon, J. Hussain, and E. Basher, "Solar radiation approximation using sunshine hour at Patenga, Bangladesh," in 8th International Conference on Electrical and Computer Engineering, pp. 321-324, Dhaka, Bangladesh, 2014.

[14] M. R. Alrashidi and M. F. Alhajri, "Particle swarm optimization and its applications in power systems," in Computational Intelligence in Power Engineering, pp. 295-324, Springer, 2010.

[15] S. Devi and M. Geethanjali, "Optimal location and sizing determination of distributed generation and DSTATCOM using particle swarm optimization algorithm," International Journal of Electrical Power \& Energy Systems, vol. 62, pp. 562-570, 2014.

[16] M. Abdel-Salam, M. T. El-Mohandes, and E. Shaker, "PSObased performance improvement of distribution systems using DG sources," in 2016 Eighteenth International Middle East Power Systems Conference (MEPCON), Cairo, Egypt, 2016.

[17] M. J. Tahir, I. A. Latiff, M. Alam, and M. S. Mazliham, "Network reconfiguration using modified particle swarm algorithm," in 2018 2nd International Conference on Smart Sensors and Application (ICSSA), pp. 1-5, Kuching, Malaysia, 2018.

[18] M. Q. Duong, T. D. Pham, T. T. Nguyen, A. T. Doan, and H. Tran, "Determination of Optimal Location and Sizing of Solar Photovoltaic Distribution Generation Units in Radial Distribution Systems," Energies, vol. 12, no. 1, p. 174, 2019.

[19] E. Ciprés, Analysis of the implementation of a photovoltaic plant in distribution system [M.S. thesis], Politechnika Łódzka, Catalonia, 2011.

[20] A. A. Kadir, A. Mohamed, and H. Shareef, Eds., "Harmonic impact of grid connected photovoltaic inverters on $13.8 \mathrm{kV}$ distribution system," in Regional Engineering Postgraduate Conference EPC, Malaysia, 2010.

[21] D. Committee, I. Power, and E. Society, IEEE Recommended Practice and Requirements for Harmonic Control in Electric Power Systems IEEE Power and Energy Society, The Institute of Electrical and Electronics Engineers, 2014.

[22] N. Nagaraja, M. T. Student, A. Pradesh, and A. Pradesh, "Study on performance characteristics of PV array under non-uniform irradiation conditions," International Advanced Research Journal in Science, Engineering and Technology, vol. 3, no. 11, pp. 187-193, 2016. 